Article

\title{
Transcriptome Analysis Identifies ALCAM Overexpression as a Prognosis Biomarker in Laryngeal Squamous Cell Carcinoma
}

\author{
Pedro Nicolau-Neto ${ }^{1}$ (D), Paulo Thiago de Souza-Santos ${ }^{2}$ (D), Mariana Severo Ramundo ${ }^{1}$, \\ Priscila Valverde ${ }^{3}$, Ivanir Martins ${ }^{3}$, Izabella Costa Santos ${ }^{4}$ ( ) , Fernando Dias ${ }^{4}$, \\ Tatiana de Almeida Simão ${ }^{5}$ and Luis Felipe Ribeiro Pinto ${ }^{1,5, *}$ \\ 1 Programa de Carcinogênese Molecular, Instituto Nacional de Câncer-INCA, Rua Andre Cavalcanti 37, \\ Rio de Janeiro, RJ CEP 20231-050, Brazil; pedronicolau.n@gmail.com (P.N.-N.); \\ marianasevero@gmail.com (M.S.R.) \\ 2 Laboratório de Hanseníase, Instituto Oswaldo Cruz-Fiocruz, Av. Brasil, 4365 - Manguinhos, Rio de Janeiro, \\ RJ CEP 21040-900, Brazil; pthiagoss@gmail.com \\ 3 Divisão de Patologia, Instituto Nacional de Câncer-INCA, Rua Cordeiro da Graça, 156, Rio de Janeiro, \\ RJ CEP 20220-400, Brazil; pvalverde@inca.gov.br (P.V.); ioliveira21@hotmail.com (I.M.) \\ 4 Seção de Cirurgia de Cabeça e Pescoço, Instituto Nacional de Câncer-INCA, Praça da Cruz Vermelha, Rio \\ de Janeiro, RJ CEP 20230130, Brazil; ibellacs@yahoo.com.br (I.C.S.); fdiasmd@yahoo.com.br (F.D.) \\ 5 Departamento de Bioquímica, IBRAG, Universidade do Estado do Rio de Janeiro, Av. 28 de Setembro 87, \\ Fundos, Pavilhão Américo Piquet Carneiro-4 ${ }^{\circ}$ andar, Rio de Janeiro, RJ CEP 20551-030, Brazil; \\ tasimao@gmail.com \\ * Correspondence: lfrpinto@inca.gov.br; Tel.: +55-21-3207-6598
}

Received: 13 January 2020; Accepted: 14 February 2020; Published: 18 February 2020

\begin{abstract}
Background: Laryngeal squamous cell carcinoma (LSCC) is one of the most incident tumors in the world, especially in developing countries, such as Brazil. Different from other tumors, LSCC prognosis did not improve during the past four decades. Therefore, the objective of this study was to develop biomarkers that can predict LSCC patient's prognosis. Results: Transcriptome analysis pointed out 287 overexpressed genes in LSCC in comparison to adjacent mucosa. Among these, a gene-pattern signature was created with 24 genes associated with prognosis. The Bayesian clustering of both Brazil and The Cancer Genome Atlas (TCGA) data pointed out clusters of samples possessing significative differences in the prognosis, and the expression panel of three genes ( $A L C A M, G B P 6$, and $M E 1$ ) was capable to distinguish patients with worse prognosis with an accuracy of $97 \%$. Survival analyses with TCGA data highlighted ALCAM gene expression as an independent prognostic factor for LSCC. This was further confirmed through immunohistochemistry, using a validation set of Brazilian patients. ALCAM expression was not associated with prognosis for other head and neck tumor sites. Conclusion: ALCAM overexpression seems to be an independent prognosis biomarker for LSCC patients.
\end{abstract}

Keywords: laryngeal squamous cell carcinoma; transcriptome analysis; prognostic biomarker; ALCAM

\section{Introduction}

Laryngeal squamous cell carcinoma (LSCC) is a highly incident and mortal disease [1], affecting mainly the male population of medium- and low-income countries, such as Brazil that presents the fourth highest incidence of this disease in the world [2,3]. LSCC diagnosis and treatment is multidisciplinary, with the employment of different procedures. Nevertheless, $60 \%$ of patients present 
advanced disease, and LSCC is one of few tumors with decreasing five-year survival rates over the past 40 years $[4,5]$. Consequently, there is a demand to improve therapy response.

The application of molecular biomarkers in the diagnosis, prognosis, and treatment choice was essential to reduce the mortality rates of prostate, breast, colorectal, and lung cancer [6-9]. Recently, The Cancer Genome Atlas (TCGA) consortium published a comprehensive molecular study on head and neck squamous cell carcinoma (HNSCC) [10]. However, not only several molecular alterations were not site-specific, but also, they were not analyzed regarding clinicopathological features [11]. There is a lack of a more comprehensive molecular analyses concerning LSCC prognosis [5], resulting in gene-specific or small gene panel analyses. So, at the somatic level, mutations in CDKN2A and TP53, and copy number alterations in CDKN2A, PIK3CA, and HER2 were associated with worse survival rates of patients with LSCC. Besides, analysis of mutations in CDKN2A and TP53 in laryngeal dysplasia could predict lesions that would develop into a tumor [12-14]. In addition, hypermethylation of CDKN2A gene body was associated with better locoregional control after surgery [15], and LMX1B hypermethylation was associated with worse overall and disease-free survival rates [16]. Additionally, the expression of long noncoding RNAs, such as CCAT1, DGR5, H19, and HOTAIR, were also associated with LSCC prognosis and diagnosis [17]. The signature of claudin expression, specifically claudin 1,3, 7 , and 8 , was associated with early diagnosis and metastasis identification and related to prognosis [18], whereas the analysis of tumor-associated immune cells components, especially CD3, CD4, CD8, CD68, and CD163 positive cells, was described as useful to predict the response of immunological checkpoint inhibitor therapy [19].

Therefore, the objective of this study was to identify biomarkers associated with LSCC prognosis. To achieve it, we carried out a transcriptomic analysis and validated the identified genes in our own validation set of samples, and also in the TCGA database, revealing ALCAM overexpression as an independent prognostic factor for LSCC patients.

\section{Results}

\subsection{Identifying Molecular Prognostic Biomarker for LSCC Patients}

Transcriptome analysis revealed 725 differentially expressed genes (DEG), 287 overexpressed and 438 underexpressed, in LSCC when compared to nonmalignant surrounding mucosa (NSM) (Table S1). These DEGs were related to cell signaling pathways associated with neoplastic progression, such as cell-extracellular matrix interaction, focal adhesion, PI3K/AKT, and small cell lung cancer-associated pathway.

Among the 287 overexpressed genes, 24 were associated with prognosis (log-rank $p$-value $<0.05)$, creating a suggestive prognostic gene-pattern expression signature panel of LSCC (Table 1). Therefore, the expression value of this prognostic gene-pattern signature was used in clustering LSCC samples in the investigation set of samples, resulting in two groups with significative differences in prognosis. Cluster 1 contained samples from patients who presented better prognosis (median survival 129.4 months) than patients grouped in Cluster 2 (median survival 14.10 months) ( $p=0.0002$, Harzard Ratio $(\mathrm{HR})=45.41,95 \%$ confidence interval $(\mathrm{CI})=6.19-333.0)$ (Figure 1A). Applying this gene set to TCGA data, three clusters of LSCC samples were observed. Cluster 3 showed a five-year survival rate of $36.3 \%$, presenting a significative worse prognosis than samples from Clusters 1 and 2, which possessed a five-year survival rate of $65.4 \%$ (Figure 1B).

The ROC (receiving operating characteristic) curve analysis with all 24 genes applied to TCGA validation set revealed area under curve (AUC) of 1.0 to detect LSCC patients with worse prognosis, and the same result was observed when using as a minimal subset of 12 genes (ADH7, ALCAM, CYP2C19, GBP6, LYPD6B, TPD52L1, ODC1, BTBD11, PTGR1, ME1, C12ORF75, and ACVR1). Further analysis reducing the number of genes from the panel revealed that with three genes (ALCAM, GBP6, and ME1) we could reach an accuracy of 0.97 (sensitivity of $94.7 \%$ and specificity of $93.1 \%$ ). Further reduction in the number of genes caused a significant loss of accuracy (Figure 1C,D). 
A
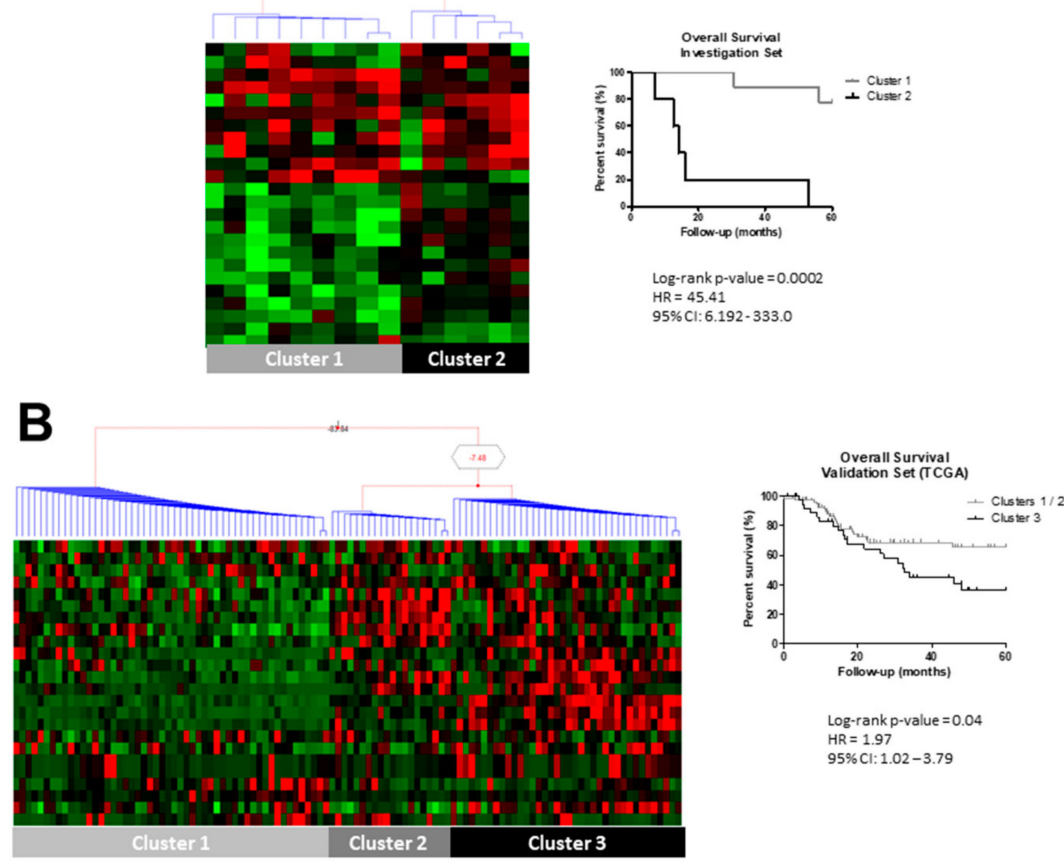

$H R=1.97$

$95 \%$ Cl: $1.02-3.79$

C

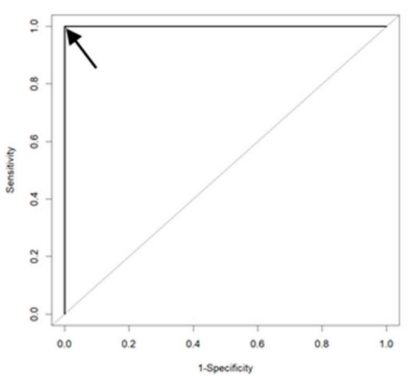

D

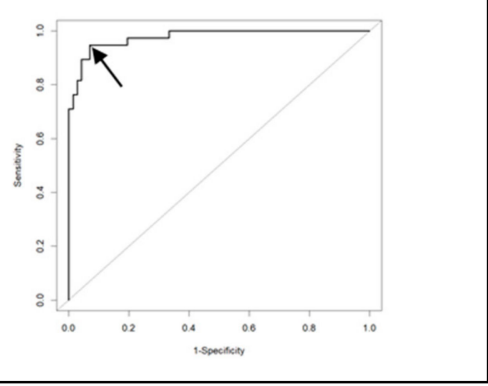

Figure 1. Laryngeal squamous cell carcinoma (LSCC) transcriptome analysis pointed out the gene expression signature associated with prognosis. (A) Bayesian hierarchical clustering with the expression of gene-pattern signature associated with LSCC prognosis was capable to segregate Brazilian National Cancer Institute (INCA) LSCC samples into two clusters. Kaplan-Meier curve analysis shows prognosis differences between LSCC samples according to gene-expression signature, with Cluster 1 samples presenting a significative better prognosis than Cluster 2 samples. (B) Applying the gene-prognosis panel to The Cancer Genome Atlas (TCGA) LSCC samples revealed three clusters from Bayesian hierarchical clustering, and Cluster 3 presented a worse prognosis than samples from Clusters 1 and 2. In the heatmaps, each column represents an individual sample and each line represents a gene expression. The red and green colors represent increased and decreased gene expression, respectively. Groups were made according to 24 overexpressed gene expressions associated with prognosis. (C) The 12-gene-expression panel (ADH7, ALCAM, CYP2C19, GBP6, LYPD6B, TPD52L1, ODC1, BTBD11, PTGR1, ME1, C12ORF75, and ACVR1) was capable to distinguish samples of Cluster 3, which presented worse prognosis, from those from Clusters 1 and 2 with an AUC of 1.0. (D) A three-gene panel with ALCAM, GBP6, and ME1 expression values showed similar results to those from 12-gene panel, showing AUC of 0.97, sensitivity $94.7 \%$, and specificity $93.1 \%$. Legend: HR, hazard ratio; CI, confidence interval; black arrow represents the selected ROC curve point. 
Table 1. Overexpressed genes associated to LSCC prognosis in the validation set of samples.

\begin{tabular}{ccc}
\hline Gene Symbol & Official Full Name & Log-Rank $p$-Value \\
\hline ACOX1 & acyl-CoA oxidase 1 & 0.007 \\
ACVR1 & activin A receptor type 1 & 0.007 \\
ADH7 & alcohol dehydrogenase 7 & 0.005 \\
AGFG2 & ArfGAP with FG repeats 2 & 0.010 \\
ALCAM & activated leukocyte cell adhesion molecule & 0.007 \\
BTBD11 & BTB domain containing 11 & 0.003 \\
C12orf75 & chromosome 12 open reading frame 75 & 0.010 \\
CDK14 & cyclin dependent kinase 14 & 0.045 \\
CYP2C19 & cytochrome P450 family 2 subfamily C member 19 & 0.005 \\
GBP6 & guanylate binding protein family member 6 & 0.045 \\
GLTP & glycolipid transfer protein & 0.045 \\
GNG4 & G protein subunit gamma 4 & 0.010 \\
LOX & lysyl oxidase & 0.045 \\
LYPD6B & LY6/PLAUR domain containing 6B & 0.013 \\
ME1 & malic enzyme 1 & 0.045 \\
NPEPPS & aminopeptidase puromycin sensitive & 0.045 \\
ODC1 & ornithine decarboxylase 1 & 0.003 \\
PMM1 & Phosphomannomutase 1 & 0.016 \\
PTGR1 & prostaglandin reductase 1 & 0.000 \\
SERPINA3 & serpin family A member 3 & 0.045 \\
ST3GAL4 & tumor protein D52-like 1 & 0.045 \\
TPD52L1 & zinc finger protein 750 & 0.045 \\
ZDHHC13 & ST3 beta-galactoside alpha-2,3-sialyltransferase 4 & 0.010 \\
ZNF750 & & 0.045 \\
\hline
\end{tabular}

To validate the prognostic value of each individual gene present in the gene panel, we conducted univariate survival analyses using LSCC data from TCGA, with ALCAM $(p=0.01), \operatorname{BTBD11}(p=0.20)$, $\operatorname{LOX}(p=0.04)$, and LYPD6B $(p=0.16)$ being maintained for Cox regression multivariate analysis. Final Cox regression model showed involved surgical margins ( $p=0.001, \mathrm{HR}=4.11,95 \% \mathrm{CI}=1.75-9.66)$, and ALCAM expression ( $p=0.010, \mathrm{HR}=2.74,95 \% \mathrm{CI}=1.26-5.97)$ as independent prognostic factors (Table 2; Figure 2A). The ALCAM gene overexpression association with prognosis was exclusive for LSCC in the HNSCC TCGA data, and was not observed either when all HNSCC samples were analyzed together $(p=0.97$ ), or according to other specific sites (oral cavity (OCSCC), $p=0.34$; and oropharyngeal (OPSCC), $p=0.36$ ) (Figure 2B-D).

Aiming to understand possible reasons behind overexpression of ALCAM, we also analyzed ALCAM somatic alterations in the LSCC TCGA dataset. ALCAM was amplified in $11.8 \%$ of LSCC samples, showing association with the expression levels $(p=0.018)$. Only one sample showed a missense mutation, with unknown biological significance (Figure S1).

Table 2. Survival analyses pointed out $A L C A M$ gene expression as independent prognostic factor in LSCC.

\begin{tabular}{|c|c|c|c|c|c|c|c|}
\hline \multirow{2}{*}{ Feature } & \multirow{2}{*}{ Categories } & \multicolumn{3}{|c|}{ Univariate Analysis } & \multicolumn{3}{|c|}{ Multivariate Analysis } \\
\hline & & HR & $(95 \% \mathrm{CI})$ & $p$ Value & HR & $(95 \% \mathrm{CI})$ & $p$ Value \\
\hline \multicolumn{8}{|c|}{ LSCC TCGA Provisional Data $(n=110)$} \\
\hline Age at diagnosis (years) & $>62$ vs. $<62$ & 1.19 & $(0.67-2.12)$ & 0.54 & & & \\
\hline Tumor Stage & III-IV vs. I-II & 0.74 & $(0.31-1.77)$ & 0.51 & & & \\
\hline Tumor Differentiation & G3 vs. G2 vs. G1 & 0.69 & $(0.43-1.12)$ & 0.14 & 0.98 & $(0.34-2.82)$ & 0.980 \\
\hline Perineural Invasion & Yes vs. No & 3.97 & $(1.67-9.47)$ & 0.001 & 2.50 & $(0.92-6.73)$ & 0.069 \\
\hline Surgical Margins & Positive/Close vs. Negative & 4.20 & $(1.79-9.83)$ & 0.0009 & 4.11 & $(1.75-9.66)$ & 0.001 \\
\hline$A C O X 1$ & High vs. Low & 1.04 & $(0.59-1.85)$ & 0.86 & & & \\
\hline ACVR1 & High vs. Low & 1.26 & $(0.70-2.25)$ & 0.43 & & & \\
\hline ADH7 & High vs. Low & 1.05 & $(0.59-1.87)$ & 0.84 & & & \\
\hline AGFG2 & High vs. Low & 0.75 & $(0.42-1.33)$ & 0.33 & & & \\
\hline$A L C A M$ & High vs. Low & 2.05 & $(1.13-3.69)$ & 0.01 & 2.74 & $(1.26-5.97)$ & 0.010 \\
\hline BTBD11 & High vs. Low & 1.44 & $(0.81-2.54)$ & 0.20 & 2.26 & $(0.72-7.06)$ & 0.158 \\
\hline
\end{tabular}


Table 2. Cont.

\begin{tabular}{|c|c|c|c|c|c|c|c|}
\hline \multirow{2}{*}{ Feature } & \multirow{2}{*}{ Categories } & \multicolumn{3}{|c|}{ Univariate Analysis } & \multicolumn{3}{|c|}{ Multivariate Analysis } \\
\hline & & HR & $(95 \% \mathrm{CI})$ & $p$ Value & HR & $(95 \%$ CI $)$ & $p$ Value \\
\hline C12ORF75 & High vs. Low & 1.04 & $(0.59-1.86)$ & 0.87 & & & \\
\hline CDK14 & High vs. Low & 0.92 & $(0.51-1.66)$ & 0.78 & & & \\
\hline CYP2C19 & High vs. Low & 1.23 & $(0.70-2.18)$ & 0.45 & & & \\
\hline GBP6 & High vs. Low & 1.09 & $(0.61-1.94)$ & 0.75 & & & \\
\hline GLTP & High vs. Low & 0.90 & $(0.51-1.61)$ & 0.74 & & & \\
\hline GNG4 & High vs. Low & 1.44 & $(0.81-2.54)$ & 0.21 & & & \\
\hline LOX & High vs. Low & 1.81 & $(1.01-3.24)$ & 0.04 & 1.99 & $(0.66-6.02)$ & 0.218 \\
\hline LYPD6B & High vs. Low & 0.65 & $(0.36-1.18)$ & 0.16 & 0.60 & $(0.18-1.95)$ & 0.402 \\
\hline ME1 & High vs. Low & 1.14 & $(0.64-2.02)$ & 0.64 & & & \\
\hline NPEPPS & High vs. Low & 1.16 & $(0.65-2.05)$ & 0.60 & & & \\
\hline ODC1 & High vs. Low & 1.38 & $(0.78-2.46)$ & 0.26 & & & \\
\hline PMM1 & High vs. Low & 1.21 & $(0.68-2.15)$ & 0.49 & & & \\
\hline PTGR1 & High vs. Low & 1.31 & $(0.74-2.33)$ & 0.34 & & & \\
\hline SERPINA3 & High vs. Low & 1.44 & $(0.39-1.23)$ & 0.21 & & & \\
\hline ST3GLA4 & High vs. Low & 0.80 & $(0.45-1.43)$ & 0.46 & & & \\
\hline TPD52L1 & High vs. Low & 0.85 & $(0.48-1.51)$ & 0.59 & & & \\
\hline ZDHHC13 & High vs. Low & 0.97 & $(0.55-1.71)$ & 0.91 & & & \\
\hline ZNF750 & High vs. Low & 0.90 & $(0.51-1.60)$ & 0.73 & & & \\
\hline
\end{tabular}

Footnote: HR, hazard ratio; G1, G2, and G3 represent well, moderately, and poorly differentiated, respectively.

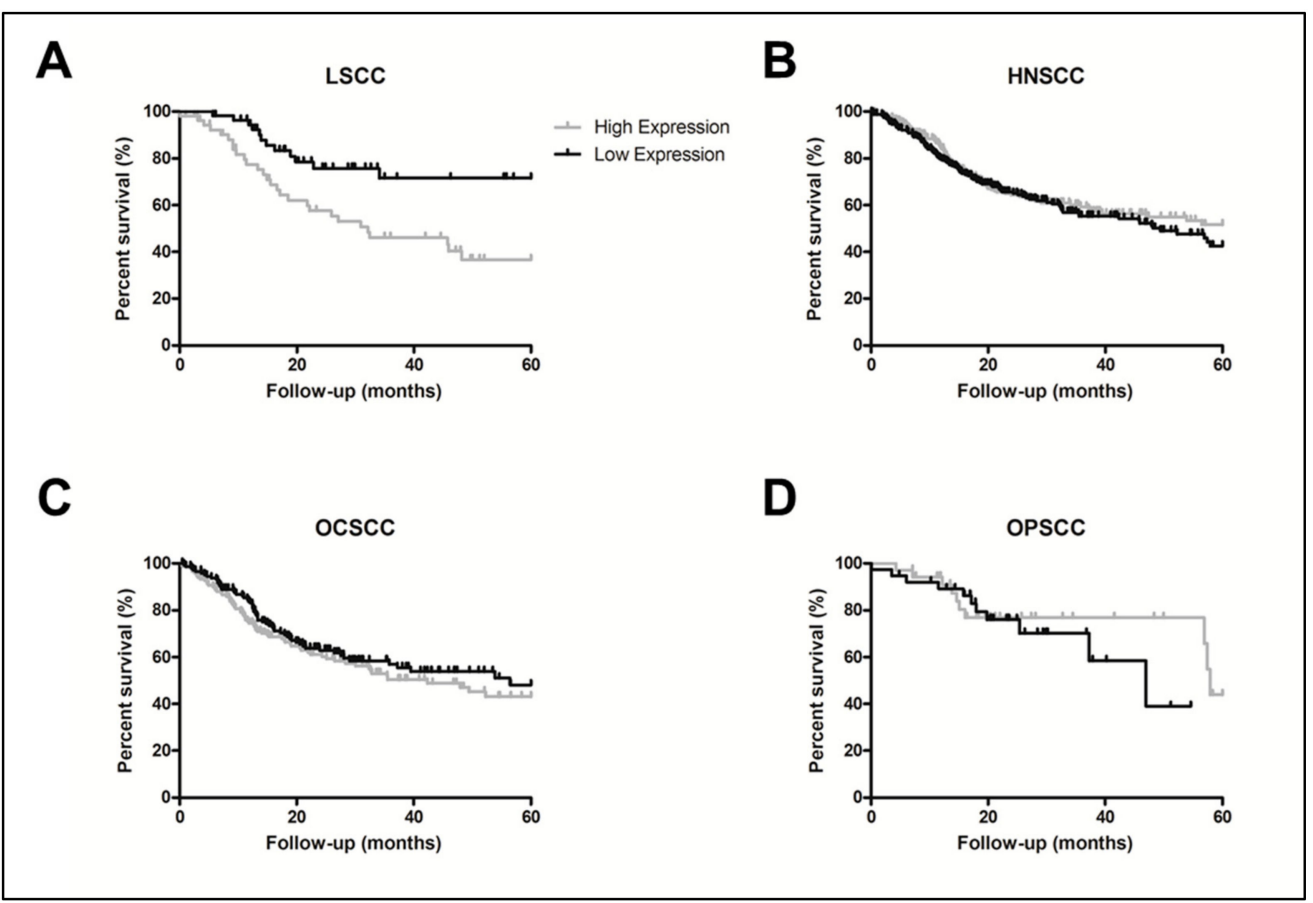

Figure 2. ALCAM overexpression confers worse prognosis to LSCC patients. (A) LSCC presenting ALCAM low expression have a better prognosis than LSCC overexpressing ALCAM $(p=0.01, \mathrm{HR}=2.74$, 95\% CI 1.26-5.97). The association with prognosis seems to be specific to LSCC among HNSCC tumors. ALCAM expression was not associated with prognosis analyzing all head and neck squamous cell carcinoma (HNSCC) together (B) or separately, oral cavity (OCSCC) (C) and oropharnyngeal (OPSCC) (D). Legend: Black line, ALCAM low expression; grey line, ALCAM high expression. Groups were made according to $A L C A M$ expression median value.

\subsection{ALCAM Protein High Levels Was also Associated to LSCC Worse Prognosis}

In order to validate the association between ALCAM overexpression and LSCC prognosis, we evaluated ALCAM protein expression by immunohistochemistry in 44 LSCC samples (Figure 3A-L). This analysis showed that 12 tumors $(27.3 \%)$ had no ALCAM expression, while $32(72.7 \%)$ presented positive ALCAM immunostaining. The median percentage of positive staining cells was $20 \%$, and this value was used as cut-off for classifying samples with low or high ALCAM levels. In this way, eight samples (25\%) presented low ALCAM levels, and 24 (75\%) tumors presented high 
expression. ALCAM immunostaining was restricted to cell membranes and presented a direct correlation with ALCAM gene expression $(r=0.37, p=0.029,95 \% \mathrm{CI}=0.03-0.63)$ (Figure S2). ALCAM protein immunohistochemical analysis confirmed the worse prognosis associated with ALCAM gene overexpression. Patients with high ALCAM levels presented a lower median survival time (30.7 months) compared to those tumors showing low or negative ALCAM levels (137.9 months), and high ALCAM protein levels was also an independent prognostic factor for LSCC $(p=0.04, \mathrm{HR}=2.31,95 \%$ $\mathrm{CI}=1.03-5.28$ ) (Figure 3M). No association was observed between ALCAM protein levels and LSCC clinical-pathological characteristics.

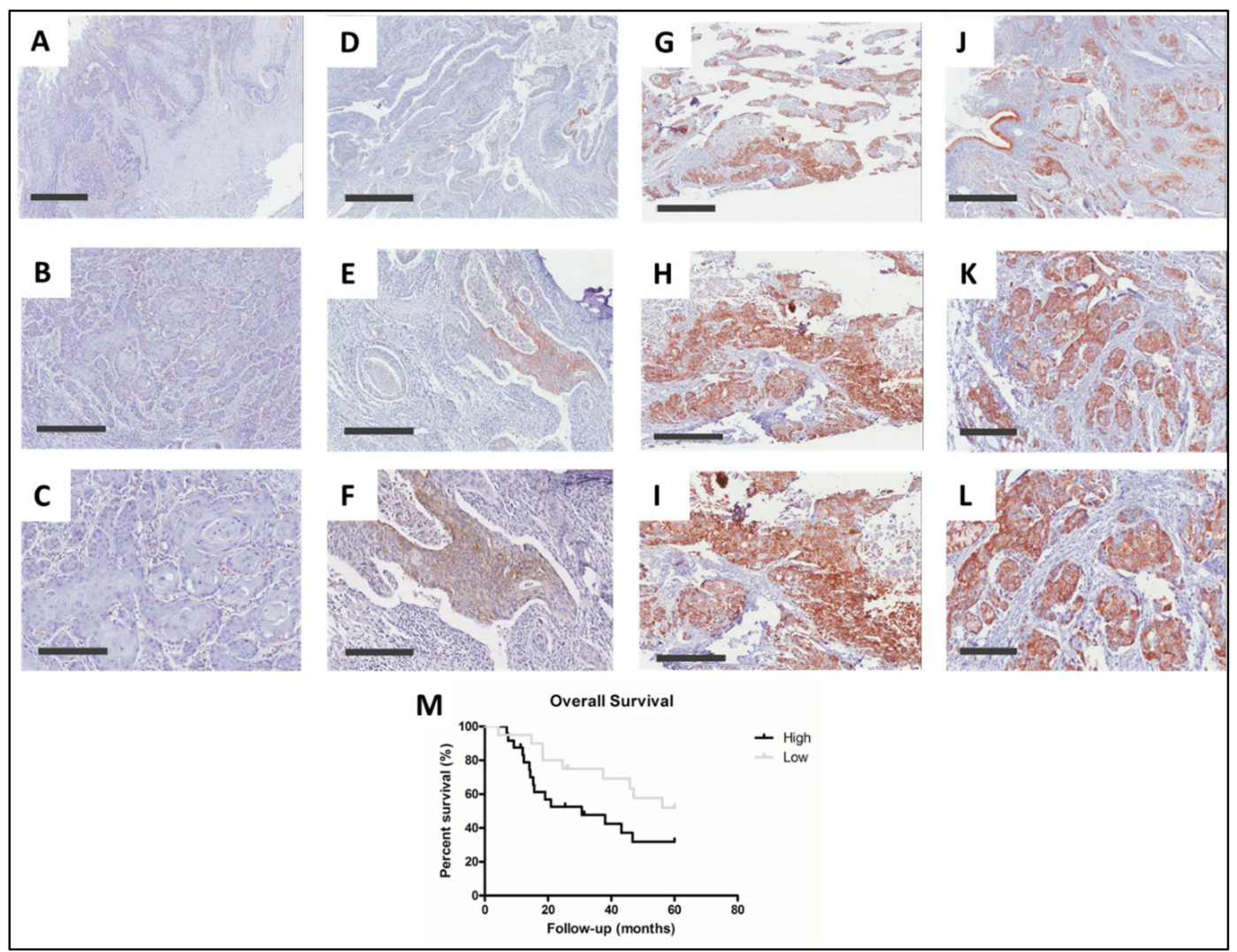

Figure 3. ALCAM protein levels in LSCC and its association to prognosis. Representative micrographs of ALCAM protein expression analysis by immunohistochemistry performed in 44 LSCC. In this analysis, 27.3\% of LSCC showed no ALCAM expression (A-C). Among ALCAM positive tumors, 25\% of samples showed expression in less than $20 \%$ of cells being categorized as low ALCAM expression (D-F). LSCC samples with more than $20 \%$ of positive cells were categorized as high ALCAM expression (G-L). (G-I) Representative LSCC with ALCAM staining in 70\% of cells. (J-L) Representative LSCC with ALCAM staining in 80\% of cells. (M) LSCC presenting ALCAM protein low levels have a better prognosis than LSCC overexpressing ALCAM protein $(p=0.04, \mathrm{HR}=2.31,95 \%$ CI $1.03-5.28) .(\mathbf{A}, \mathbf{D}, \mathbf{G}, \mathbf{J})$ grey bar represents scale $1 \mathrm{~mm}$. (B,E,H,K) grey bar represents scale $400 \mu \mathrm{m},(\mathbf{C}, \mathbf{F}, \mathbf{I}, \mathbf{L})$ grey bar represents $200 \mu \mathrm{m}$. Black line, ALCAM high levels; grey line, ALCAM low levels. Groups were made according to ALCAM median value of positive cells.

\section{Discussion}

LSCC is one of the few tumors that have presented decreasing overall survival rates during the past decades. Therefore, in this manuscript we developed a gene-expression panel that is strongly associated with LSCC patient's prognosis. Among the 24 genes that made the panel, ALCAM gene and protein expression was shown to be an independent prognostic factor for LSCC.

Activated leukocyte cell adhesion molecule (ALCAM) gene is located at human chromosome $3 q 13.11$ [20], and encodes a transmembrane glycoprotein, which acts in the cell-cell adhesion, either in 
homotypic (ALCAM-ALCAM) or in heterotypic (ALCAM-CD6) interactions between adjacent cells [21]. ALCAM expression could be detectable in a variety of tissues and cells under certain spatial and temporal controls during development [14]. In homeostasis, homotypic ALCAM interactions could modulate epithelial and endothelial cells' interactions and neuronal guidance, while ALCAM-CD6 heterotypic interaction shows physiological relevance in antigen presentation in immune cell adhesion [22-25]. Several studies show a role for CD6 as a co-stimulatory molecule in T-cell activation [26,27] and the ALCAM-CD6 interaction was described as pivotal for antigen presentation [28,29]. Interestingly, it was observed that the molecule I/F8 scFv induces ALCAM internalization and the conjugation between I/F8 scFv and the saporin immunotoxin efficiently kill ALCAM-positive tumor cells selectively [30]. Additionally, vaccine-induced cytotoxic T-lymphocytes can recognize an epitope expressed by ALCAM and this could be useful as a novel mechanism of induction of potent tumor-specific cellular responses by mimotopes of tumor-associated carbohydrate antigens [31].

ALCAM seems to characterize cancer stem cells (CSC) in some tumors and ALCAM was highly expressed in intestinal stem cell niche, with an association to intestinal carcinoma progression, including benign and metastatic tumors [32]. Subpopulation of nonsmall cell lung cancer (NSCLC) triple-positive for EPCAM, ALCAM, and CD44 possessed CSC characteristics, including being highly proliferative, having greater clonogenicity, ability for self-renewal through spheroid formation, and chemoresistance [33]. Recently, ALCAM-E3 ligase-mediated degradation was associated with CSC features' regulation in HNSCC cells [34]. Besides, ALCAM membrane expression was considered a CSC marker in OCSCC-derived cell lines [35]. We are going to carry out in vitro analysis with LSCC cell lineages to try to understand the role of ALCAM overexpression in LSCC prognosis.

The long arm of chromosome 3, which presents the ALCAM gene, is a classically amplified genomic region in squamous carcinomas, particularly in esophageal squamous cell carcinoma and HNSCC [10,11]. However, only $12 \%$ of LSCC samples presented ALCAM copy number gain/amplification associated with its overexpression, suggesting that further mechanisms, such as DNA methylation, already shown to be associated with ALCAM overexpression in breast tumors [36], may also be associated with this deregulation in LSCC.

Although our data pointed out ALCAM gene expression association only with the prognosis of LSCC patients among HNSCC, our study was the only one that evaluated this marker in the larynx exclusively. In other HNSCC studies, ALCAM protein overexpression, evaluated by immunohistochemistry, was already related as an independent prognostic factor for OCSCC, associated with the sonic hedgehog signaling pathway [37], or Epidermal Growth Factor Receptor (EGFR) activation [38], in the Chinese population. In a similar way, ALCAM protein level was described as potential biomarkers for predicting tumor behavior and prognosis of salivary gland tumor in Iranian patients [39]. Recently, Clauditz et al. [40] evaluated the ALCAM protein expression in HNSCC, including LSCC samples, combining in the same group of samples laryngeal and hypopharyngeal tumors, and observed a discordant result to our findings, being ALCAM expression mainly cytoplasmic, and not associated with the prognosis of LSCC patients.

Recently, studies have proposed the potential use of gene-expression signature to measure the prognosis of LSCC patients, employing both protein-coding and -noncoding genes. Concerning protein-coding genes, a panel of 26 hypoxia-related genes was associated with the improvement of hypoxia-modifying treatment in laryngeal cancer [41], and the expression of 18 inflammatory-associated genes was capable to distinguish LSCC samples according to prognosis with AUC of 0.61 [42]. A panel of two long noncoding RNAs was also associated with LSCC prognosis presenting AUC of 0.69 [43]. The limited number of studies that propose biomarkers for LSCC prognosis reflects in only one clinical trial recruiting LSCC patients according to a biomarker, aiming to block PD1/PD-L1 interaction.

Although our transcriptomic analysis was conducted in a limited number of samples, it was one of the few studies that evaluated exclusively LSCC, separate from the large HNSCC group. Moreover, our data exposed the prognostic value of the gene panel and ALCAM in both Brazilian and TCGA samples. Besides the prognostic value of ALCAM expression measurement, our study pointed out 
a valuable prognostic gene-expression signature, which shows high power to discriminated LSCC samples regarding their patient's outcome (12-genes signature AUC 1.00, 3-genes signature ROC 0.97), which can improve the treatment option and patient monitoring, aiming to improve treatment response.

\section{Materials and Methods}

\subsection{LSCC Samples}

A total of 44 LSCC and paired nonmalignant surrounding mucosa (NSM, histopathologically adjacent normal mucosa, $3 \mathrm{~cm}$ from tumor borders) samples were collected from 2008 to 2014 by the Head and Neck Surgical Division of the Instituto Nacional de Câncer (INCA, Rio de Janeiro, Brazil) from patients who had not undergone chemo- or radiotherapy treatment. Histopathological profiling was evaluated by the Pathology Department of INCA. All patients signed an informed consent form, and the project was approved by the institution's Ethics Committee.

Among these set of LSCC and NSM samples, 14 LSCC and 12 NSM samples were randomly selected (investigation set of samples) for transcriptome analysis. The first validation set to confirm gene expression by qPCR and immunohistochemistry analysis were conducted with samples from all 44 patients. A second validation set was composed by the Head and Neck provisional data from TCGA consortium [10]. TCGA data were analyzed with the web-based software cBioPortal [44,45]. Patients' clinical and pathological features are described in Table 3.

\subsection{LSCC Gene-Expression Profiling}

RNA of all samples was isolated from frozen tissue with the RNeasy Mini Kit (Qiagen, Inc, Hilden, Germany). RNA of the investigation set of samples was converted to complementary DNA (cDNA) with WT Expression Kit, biotinylated, and applied to GeneChip Human Exon 1.0 ST array (Affymetrix, Inc., Santa Clara, CA, USA), as previously described [46]. The raw data were normalized in the Expression Console software (Affymetrix) using the robust multi-array average (RMA) method. Subsequent analysis of gene expression was carried out in R environment, using the limma package, available from the Bioconductor project, to obtain quantitative expression levels for coding genes. Differentially expressed genes (DEG) were classified by the following criteria: $p<0.05$ and fold-change expression cutoff |2.0|. Microarray data are available at Gene Expression Omnibus Accession Browser (accession number GSE143224) [47-49].

\subsection{Prognostic Gene-Pattern Signature}

The prognostic value of all overexpressed genes was evaluated using the microarray data herein performed. For this purpose, we analyzed each gene expression regarding its association with the patient's prognosis in the investigation set of samples. Higher and lower gene expression were defined, using as cut-off the median expression value. Genes with log-rank $p$-value $<0.05$ were used for the Bayesian hierarchical clustering of both investigation and validation set of samples followed by survival analysis between clusters of samples. Receiver-operating characteristic (ROC) curves and the area under the ROC curve (AUC), as well as the sensitivity and specificity values, were used to assess the feasibility of using messenger RNA (mRNA) expression levels as prognostic biomarkers for LSCC patients. Initially, all prognostic-associated gene expressions were included in the ROC curve analysis. Genes were removed from the ROC curve analysis following the backward stepwise method regarding the gene individual AUC value, which resulted in a ROC curve with the lower number of genes possessing significantly high AUC. Survival analyses, Bayesian clustering, and ROC curve analyses were conducted in R using the survival packages, BHC and Epi, respectively [50-52]. 
Table 3. Clinicopathological data of investigation and validation set of samples.

\begin{tabular}{|c|c|c|c|c|c|c|c|c|c|}
\hline \multirow{3}{*}{ Feature } & & \multirow{2}{*}{\multicolumn{2}{|c|}{$\begin{array}{c}\text { Brazilian Samples } \\
(n=44)\end{array}$}} & \multirow{2}{*}{\multicolumn{2}{|c|}{$\begin{array}{c}\text { Investigation Set } \\
\text { Brazilian Transcriptome }(n=14)\end{array}$}} & \multirow{2}{*}{\multicolumn{2}{|c|}{$\begin{array}{c}\text { Validation Set } \\
\text { TCGA Data }(n=110)\end{array}$}} & \multirow{3}{*}{$p$-Value \# } & \multirow{3}{*}{$p$-Value \$ } \\
\hline & & & & & & & & & \\
\hline & & $n$ & $\%$ & $n$ & $\%$ & $n$ & $(\%)$ & & \\
\hline Age (years) & $\begin{array}{l}\text { Median } \\
\text { Range }\end{array}$ & $\begin{array}{c}62.5 \\
44-88\end{array}$ & & $\begin{array}{c}58 \\
45-77\end{array}$ & & $\begin{array}{c}62 \\
38-83\end{array}$ & & 0.81 & 0.43 \\
\hline \multirow{3}{*}{ Gender } & Male & 42 & $95.45 \%$ & 13 & $92.86 \%$ & 91 & $82.73 \%$ & \multirow[t]{3}{*}{0.46} & \multirow[t]{3}{*}{0.04} \\
\hline & Female & 2 & $4.55 \%$ & 1 & $7.14 \%$ & 19 & $17.27 \%$ & & \\
\hline & NA & 0 & & 0 & $0.00 \%$ & 0 & $0.00 \%$ & & \\
\hline \multirow{4}{*}{ Tumor Differentiation } & Well & 6 & $13.64 \%$ & 1 & $7.14 \%$ & 7 & $6.36 \%$ & \multirow{4}{*}{0.25} & \multirow{4}{*}{0.03} \\
\hline & Moderate & 34 & $77.27 \%$ & 12 & $85.71 \%$ & 70 & $63.64 \%$ & & \\
\hline & Poor & 4 & $9.09 \%$ & 1 & $7.14 \%$ & 29 & $26.36 \%$ & & \\
\hline & NA & 0 & & 0 & $0.00 \%$ & 4 & $3.64 \%$ & & \\
\hline \multirow{5}{*}{ Tumor Stage } & I & 3 & $6.82 \%$ & 1 & $7.14 \%$ & 2 & $1.82 \%$ & \multirow{5}{*}{0.62} & \multirow{5}{*}{1.00} \\
\hline & II & 1 & $2.27 \%$ & 1 & $7.14 \%$ & 9 & $8.18 \%$ & & \\
\hline & III & 7 & $15.91 \%$ & 2 & $14.29 \%$ & 19 & $17.27 \%$ & & \\
\hline & IV & 31 & $70.45 \%$ & 9 & $64.29 \%$ & 80 & $72.73 \%$ & & \\
\hline & NA & 2 & $4.55 \%$ & 1 & $7.14 \%$ & 0 & $0.00 \%$ & & \\
\hline \multirow{3}{*}{ Lymph node metastasis } & No & 16 & $36.36 \%$ & 3 & $21.43 \%$ & 39 & $35.45 \%$ & \multirow[t]{3}{*}{0.35} & \multirow[t]{3}{*}{0.70} \\
\hline & Yes & 26 & $59.09 \%$ & 9 & $64.29 \%$ & 52 & $47.27 \%$ & & \\
\hline & NA & 2 & $4.55 \%$ & 2 & $14.29 \%$ & 19 & $17.27 \%$ & & \\
\hline \multirow{3}{*}{ Perineural Invasion } & Negative & 29 & $65.91 \%$ & 7 & $50.00 \%$ & 45 & $40.91 \%$ & \multirow[t]{3}{*}{1.00} & \multirow[t]{3}{*}{1.00} \\
\hline & Positive & 15 & $34.09 \%$ & 4 & $28.57 \%$ & 24 & $21.82 \%$ & & \\
\hline & NA & 2 & $4.55 \%$ & 3 & $21.43 \%$ & 41 & $37.27 \%$ & & \\
\hline \multirow{3}{*}{ Involved Surgical Margin } & Negative & 33 & $75.0 \%$ & 11 & $78.57 \%$ & 81 & $73.64 \%$ & \multirow[t]{3}{*}{0.43} & \multirow[t]{3}{*}{0.31} \\
\hline & Positive/close & 9 & $20.45 \%$ & 3 & $21.43 \%$ & 13 & $11.82 \%$ & & \\
\hline & NA & 2 & $4.55 \%$ & 0 & $0.00 \%$ & 16 & $14.55 \%$ & & \\
\hline \multirow{3}{*}{ Tobacco Smoking } & Current/Former & 36 & $81.82 \%$ & 10 & $71.43 \%$ & 101 & $91.82 \%$ & \multirow[t]{3}{*}{0.18} & 0.17 \\
\hline & No & 5 & $11.36 \%$ & 2 & $14.29 \%$ & 6 & $5.45 \%$ & & \\
\hline & NA & 3 & $6.82 \%$ & 2 & $14.29 \%$ & 4 & $3.64 \%$ & & \\
\hline & Current/Former & 31 & $70.45 \%$ & 6 & $42.86 \%$ & 39 & $35.45 \%$ & 0.09 & 1.00 \\
\hline Alcohol Consumption & No & 5 & $11.36 \%$ & 4 & $28.57 \%$ & 7 & $6.36 \%$ & & \\
\hline & NA & 8 & $18.19 \%$ & 6 & $42.86 \%$ & 71 & $64.55 \%$ & & \\
\hline
\end{tabular}

\# Feature comparison between Investigation Set and Validation Set. \$ Feature comparison between Brazilian Samples and Validation Set. 


\subsection{Gene-Expression Validation by Quantitative PCR}

ALCAM expression was assessed by RT-qPCR. The cDNA of 44 paired LSCC and NSM was synthesized with SuperScriptIITM Reverse Transcriptase (Invitrogen ${ }^{\circledR}$ ) and quantitative PCR was carried out with the Quantifast SYBR Green PCR kit (Qiagen) in a Rotor-Gene 6000 thermal cycler (Qiagen). Gene expression quantification was performed as previously described [53]. Specific oligonucleotides were used in the expression levels analyses, as follows: ALCAM Forward 5'-AAGTGTGCAGTACGACGATGT-3'; ALCAM Reverse 5'-GGTTGCTTGAACACCTTGACT-3'; GAPDH Forward 5' CAACAGCCTCAAGATCATCAGCAA 3', GAPDH Reverse 5' AGTGATGGCATGGACTGTGGTCAT 3'. RT-qPCR analyses were conducted in triplicate, using TE-1 cells as positive control, whereas negative control reactions were performed without cDNA.

\subsection{Immunohistochemistry Analysis}

Immunohistochemistry (IHC) was performed on 3- $\mu$ m paraffin sections of all 44 LSCC cases. For ALCAM antigen retrieval, sections were incubated in a steam oven while submerged in a trilogy buffer solution (Cell Marque), for $30 \mathrm{~min}$ at $98^{\circ} \mathrm{C}$. Sections were then incubated with the primary monoclonal antibodies against ALCAM (Sigma, St. Louis, MO, USA, HPA010926, working dilution 1:1000), for at least $12 \mathrm{~h}$. Formalin-Fixed Paraffin-Embedded (FFPE) prostate carcinoma samples served as positive control staining. As the negative control, the primary antibody was replaced by the diluent solution. The detection system used was the NovoLinkTM Max Polymer Detection System (Leica Biosystems, Wetzlar, Germany), following the protocol described by the manufacturer, using diaminobenzidine as substrate (Dako). Sections were counterstained with Harris' hematoxylin. Scored cases were considered positive when at least $1 \%$ of epithelial cells were stained. LSCC samples were categorized as low and high ALCAM protein expression using the median number of positive cells as the cut-off. Samples with positive epithelial cells lower than median value were classified as low ALCAM tumors and samples with positive epithelial cells equal or higher than median value were classified as high ALCAM tumors.

\subsection{ALCAM Somatic Alterations in LSCC}

The frequency of ALCAM copy number alterations (CNA) and single nucleotides variants (SNV) in LSCC were evaluated in the LSCC of TCGA using cBioportal software, through whole exome sequencing and DNA microarray applying GISTIC 2.0 protocol [54], respectively.

\subsection{Statistical Analyses}

Differences in gene expression were evaluated using Kruskal-Wallis test, followed by Dunn's multiple comparison tests. Spearman's rank correlation was used for assessing gene and protein expression correlation. All analyses were performed with GraphPad Prism 5 software. In survival analyses using TCGA data, univariate analysis was estimated by the Kaplan-Meier method and $\log$-rank test. Variables with $p<0.2$ were selected for multivariate analysis. Finally, Cox regression was applied with the stepwise forward method [55]. R environment using the survival package was used for survival analyses. The same protocol of survival analysis was applied for immunohistochemistry data.

\section{Conclusions}

ALCAM gene and protein expression seems to be an independent prognosis biomarker to LSCC patients.

Supplementary Materials: The following are available online at http://www.mdpi.com/2072-6694/12/2/470/s1, Figure S1: Somatic alterations in ALCAM gene; Figure S2: ALCAM expression correlation between quantitative PCR (qPCR) and immunohistochemistry (IHC), Table S1: LSCC transcriptome differentially expressed genes list. 
Author Contributions: Conception and design: P.N.-N., T.d.A.S., and L.F.R.P. Acquisition of data: P.N.-N., P.T.d.S.-S., P.V., and I.M. Acquisition of patients' samples and clinical data: F.D. and I.C.S. Analysis and interpretation: P.N.-N., P.T.d.S.-S., M.S.R., and L.F.R.P., Drafting of the manuscript: P.N.-N., T.d.A.S., and L.F.R.P. Funding acquisition: T.d.A.S. and L.F.R.P. All authors have read and approved the manuscript.

Funding: This research was supported by the Swiss Bridge Foundation, Conselho Nacional de Tecnologia e Desenvolvimento Científico (CNPq), Coordenação de Aperfeiçoamento de Pessoal de Nível Superior (CAPES), and Fundação de Amparo à Pesquisa do Estado do Rio de Janeiro (FAPERJ) grants.

Conflicts of Interest: The authors declare no conflict of interest.

\section{References}

1. Siegel, R.L.; Miller, K.D.; Jemal, A. Cancer statistics, 2019. CA Cancer J. Clin. 2019, 69, 7-34. [CrossRef]

2. Bray, F.; Ferlay, J.; Soerjomataram, I.; Siegel, R.L.; Torre, L.A.; Jemal, A. Global cancer statistics 2018: GLOBOCAN estimates of incidence and mortality worldwide for 36 cancers in 185 countries. CA Cancer J. Clin. 2018, 68, 394-424. [CrossRef]

3. Ferlay, J.; Ervik, M.; Lam, F.; Colombet, M.; Mery, L.; Piñeros, M.; Znaor, A.; Soerjomataram, I.; Bray, F. Global Cancer Observatory: Cancer Today; International Agency for Research on Cancer: Lyon, France, 2019; Available online: https://gco.iarc.fr/today (accessed on 6 January 2020).

4. Strojan, P.; Haigentz, M.; Bradford, C.R.; Wolf, G.T.; Hartl, D.M.; Langendijk, J.A.; Rinaldo, A.; Eisbruch, A.; Mendenhall, W.M.; Forastiere, A.A.; et al. Chemoradiotherapy vs. total laryngectomy for primary treatment of advanced laryngeal squamous cell carcinoma. Oral Oncol. 2013, 49, 283-286. [CrossRef]

5. Steuer, C.E.; El-Deiry, M.; Parks, J.R.; Higgins, K.A.; Saba, N.F. An update on larynx cancer. CA Cancer J. Clin. 2017, 67, 31-50. [CrossRef]

6. Logothetis, C.J.; Gallick, G.E.; Maity, S.N.; Kim, J.; Aparicio, A.; Efstathiou, E.; Lin, S.H. Molecular classification of prostate cancer progression: Foundation for marker-driven treatment of prostate cancer. Cancer Discov. 2013, 3, 849-861. [CrossRef]

7. Sørlie, T.; Perou, C.M.; Tibshirani, R.; Aas, T.; Geisler, S.; Johnsen, H.; Hastie, T.; Eisen, M.B.; van de Rijn, M.; Jeffrey, S.S.; et al. Gene expression patterns of breast carcinomas distinguish tumor subclasses with clinical implications. Proc. Natl. Acad. Sci. USA 2001, 98, 10869-10874. [CrossRef]

8. Linnekamp, J.F.; Hooff, S.R.V.; Prasetyanti, P.R.; Kandimalla, R.; Buikhuisen, J.Y.; Fessler, E.; Ramesh, P.; Lee, K.A.S.T.; Bochove, G.G.W.; de Jong, J.H.; et al. Consensus molecular subtypes of colorectal cancer are recapitulated in in vitro and in vivo models. Cell Death Differ. 2018, 25, 616-633. [CrossRef] [PubMed]

9. Chen, G.; Yan, M.; Li, R.R.; Chen, W.T. Sonic Hedgehog Signalling Activation Contributes to ALCAM Over-Expression and Poor Clinical Outcome in Patients with Oral Squamous Cell Carcinoma. Chin. J. Dent. Res. 2018, 21, 31-40. [CrossRef] [PubMed]

10. Network, C.G.A. Comprehensive genomic characterization of head and neck squamous cell carcinomas. Nature 2015, 517, 576-582. [CrossRef] [PubMed]

11. Leemans, C.R.; Snijders, P.J.F.; Brakenhoff, R.H. The molecular landscape of head and neck cancer. Nat. Rev. Cancer 2018, 18, 269-282. [CrossRef] [PubMed]

12. Larque, A.B.; Conde, L.; Hakim, S.; Alos, L.; Jares, P.; Vilaseca, I.; Cardesa, A.; Nadal, A. P16(INK ${ }^{4}$ a) overexpression is associated with CDKN2A mutation and worse prognosis in HPV-negative laryngeal squamous cell carcinomas. Virchows Arch. 2015, 466, 375-382. [CrossRef]

13. Manterola, L.; Aguirre, P.; Larrea, E.; Arestín, M.; Gaafar, A.; Elorriaga, K.; Goicoechea, I.; Armesto, M.; Fernández-Mercado, M.; Zabalza, I.; et al. Mutational profiling can identify laryngeal dysplasia at risk of progression to invasive carcinoma. Sci. Rep. 2018, 8, 6613. [CrossRef] [PubMed]

14. Scheel, A.; Bellile, E.; McHugh, J.B.; Walline, H.M.; Prince, M.E.; Urba, S.; Wolf, G.T.; Eisbruch, A.; Worden, F.; Carey, T.E.; et al. Classification of TP53 mutations and HPV predict survival in advanced larynx cancer. Laryngoscope 2016, 126, E292-E299. [CrossRef] [PubMed]

15. Ben-Dayan, M.M.; Ow, T.J.; Belbin, T.J.; Wetzler, J.; Smith, R.V.; Childs, G.; Diergaarde, B.; Hayes, D.N.; Grandis, J.R.; Prystowsky, M.B.; et al. Nonpromoter methylation of the CDKN2A gene with active transcription is associated with improved locoregional control in laryngeal squamous cell carcinoma. Cancer Med. 2017, 6, 397-407. [CrossRef] 
16. Fan, L.; Zhang, A.; Deng, P. LMX1B mRNA expression and its gene body CpG methylation are valuable prognostic biomarkers for laryngeal squamous cell carcinoma. Biomed. Pharmacother. 2019, 117, 109174. [CrossRef]

17. Cossu, A.M.; Mosca, L.; Zappavigna, S.; Misso, G.; Bocchetti, M.; De Micco, F.; Quagliuolo, L.; Porcelli, M.; Caraglia, M.; Boccellino, M. Long Non-coding RNAs as Important Biomarkers in Laryngeal Cancer and Other Head and Neck Tumours. Int. J. Mol. Sci. 2019, 20, 3444. [CrossRef] [PubMed]

18. Zhou, L.; Li, Y.; Gao, W.; Huangfu, H.; Wen, S.; Zhang, C.; Zhao, Q.; Dong, Z.; Qu, C.; Li, G.; et al. Assessment of tumor-associated immune cells in laryngeal squamous cell carcinoma. J. Cancer Res. Clin. Oncol. 2019, 145, 1761-1772. [CrossRef] [PubMed]

19. Zhou, S.; Piao, X.; Wang, C.; Wang, R.; Song, Z. Identification of claudin-1, $-3,-7$ and -8 as prognostic markers in human laryngeal carcinoma. Mol. Med. Rep. 2019, 20, 393-400. [CrossRef] [PubMed]

20. Swart, G.W.; Lunter, P.C.; Kilsdonk, J.W.; Kempen, L.C. Activated leukocyte cell adhesion molecule (ALCAM/CD166): Signaling at the divide of melanoma cell clustering and cell migration? Cancer Metastasis Rev. 2005, 24, 223-236. [CrossRef]

21. Bowen, M.A.; Bajorath, J.; D’Egidio, M.; Whitney, G.S.; Palmer, D.; Kobarg, J.; Starling, G.C.; Siadak, A.W.; Aruffo, A. Characterization of mouse ALCAM (CD166): The CD6-binding domain is conserved in different homologs and mediates cross-species binding. Eur. J. Immunol. 1997, 27, 1469-1478. [CrossRef]

22. Swart, G.W. Activated leukocyte cell adhesion molecule (CD166/ALCAM): Developmental and mechanistic aspects of cell clustering and cell migration. Eur. J. Cell Biol. 2002, 81, 313-321. [CrossRef] [PubMed]

23. Masedunskas, A.; King, J.A.; Tan, F.; Cochran, R.; Stevens, T.; Sviridov, D.; Ofori-Acquah, S.F. Activated leukocyte cell adhesion molecule is a component of the endothelial junction involved in transendothelial monocyte migration. FEBS Lett. 2006, 580, 2637-2645. [CrossRef] [PubMed]

24. Zimmerman, A.W.; Joosten, B.; Torensma, R.; Parnes, J.R.; van Leeuwen, F.N.; Figdor, C.G. Long-term engagement of CD6 and ALCAM is essential for T-cell proliferation induced by dendritic cells. Blood 2006, 107, 3212-3220. [CrossRef] [PubMed]

25. Diekmann, H.; Stuermer, C.A. Zebrafish neurolin-a and -b, orthologs of ALCAM, are involved in retinal ganglion cell differentiation and retinal axon pathfinding. J. Comp. Neurol. 2009, 513, 38-50. [CrossRef] [PubMed]

26. Aruffo, A.; Bowen, M.A.; Patel, D.D.; Haynes, B.F.; Starling, G.C.; Gebe, J.A.; Bajorath, J. CD6-ligand interactions: A paradigm for SRCR domain function? Immunol Today 1997, 18, 498-504. [CrossRef]

27. Santos, R.F.; Oliveira, L.; Carmo, A.M. Tuning T Cell Activation: The Function of CD6 At the Immunological Synapse and in T Cell Responses. Curr. Drug Targets. 2016, 17, 630-639. [CrossRef] [PubMed]

28. Pinto, M.; Carmo, A.M. CD6 as a therapeutic target in autoimmune diseases: Successes and challenges. BioDrugs 2013, 27, 191-202. [CrossRef]

29. Ibáñez, A.; Sarrias, M.R.; Farnós, M.; Gimferrer, I.; Serra-Pagès, C.; Vives, J.; Lozano, F. Mitogen-activated protein kinase pathway activation by the CD6 lymphocyte surface receptor. J. Immunol. 2006, 177, 1152-1159. [CrossRef]

30. Wiiger, M.T.; Gehrken, H.B.; Fodstad, Ø.; Maelandsmo, G.M.; Andersson, Y. A novel human recombinant single-chain antibody targeting CD166/ALCAM inhibits cancer cell invasion in vitro and in vivo tumour growth. Cancer Immunol. Immunother. 2010, 59, 1665-1674. [CrossRef]

31. Kozbor, D. Cancer vaccine with mimotopes of tumor-associated carbohydrate antigens. Immunol. Res. 2010, 46, 23-31. [CrossRef]

32. Levin, T.G.; Powell, A.E.; Davies, P.S.; Silk, A.D.; Dismuke, A.D.; Anderson, E.C.; Swain, J.R.; Wong, M.H. Characterization of the intestinal cancer stem cell marker CD166 in the human and mouse gastrointestinal tract. Gastroenterology 2010, 139, 2072-2082. [CrossRef] [PubMed]

33. Satar, N.A.; Fakiruddin, K.S.; Lim, M.N.; Mok, P.L.; Zakaria, N.; Fakharuzi, N.A.; Abd Rahman, A.Z.; Zakaria, Z.; Yahaya, B.H.; Baharuddin, P. Novel triple-positive markers identified in human non-small cell lung cancer cell line with chemotherapy-resistant and putative cancer stem cell characteristics. Oncol. Rep. 2018, 40, 669-681. [CrossRef] [PubMed]

34. Xiao, M.; Yan, M.; Zhang, J.; Xu, Q.; Qi, S.; Wang, X.; Chen, W. Cancer stem-like cell related protein CD166 degrades through E3 ubiquitin ligase CHIP in head and neck cancer. Exp. Cell Res. 2017, 353, 46-53. [CrossRef] [PubMed] 
35. Yan, M.; Yang, X.; Wang, L.; Clark, D.; Zuo, H.; Ye, D.; Chen, W.; Zhang, P. Plasma membrane proteomics of tumor spheres identify CD166 as a novel marker for cancer stem-like cells in head and neck squamous cell carcinoma. Mol. Cell Proteomics 2013, 12, 3271-3284. [CrossRef] [PubMed]

36. Jeong, Y.J.; Oh, H.K.; Park, S.H.; Bong, J.G. Prognostic Significance of Activated Leukocyte Cell Adhesion Molecule (ALCAM) in Association with Promoter Methylation of the ALCAM Gene in Breast Cancer. Molecules 2018, 23, 131. [CrossRef] [PubMed]

37. Chen, F.; Zhang, Y.; Parra, E.; Rodriguez, J.; Behrens, C.; Akbani, R.; Lu, Y.; Kurie, J.M.; Gibbons, D.L.; Mills, G.B.; et al. Multiplatform-based molecular subtypes of non-small-cell lung cancer. Oncogene 2017, 36, 1384-1393. [CrossRef]

38. Jia, G.; Wang, X.; Yan, M.; Chen, W.; Zhang, P. CD166-mediated epidermal growth factor receptor phosphorylation promotes the growth of oral squamous cell carcinoma. Oral Oncol. 2016, 59, 1-11. [CrossRef]

39. Andisheh-Tadbir, A.; Ashraf, M.J.; Khademi, B.; Ahmadi, S. Clinical implication of CD166 expression in salivary gland tumor. Tumour Biol. 2015, 36, 2793-2799. [CrossRef]

40. Clauditz, T.S.; von Rheinbaben, K.; Lebok, P.; Minner, S.; Tachezy, M.; Borgmann, K.; Knecht, R.; Sauter, G.; Wilczak, W.; Blessmann, M.; et al. Activated leukocyte cell adhesion molecule (ALCAM/CD166) expression in head and neck squamous cell carcinoma (HNSSC). Pathol. Res. Pract. 2014, 210, 649-655. [CrossRef]

41. Eustace, A.; Mani, N.; Span, P.N.; Irlam, J.J.; Taylor, J.; Betts, G.N.; Denley, H.; Miller, C.J.; Homer, J.J.; Rojas, A.M.; et al. A 26-gene hypoxia signature predicts benefit from hypoxia-modifying therapy in laryngeal cancer but not bladder cancer. Clin. Cancer Res. 2013, 19, 4879-4888. [CrossRef]

42. He, Q.; Tian, L.; Jiang, H.; Zhang, J.; Li, Q.; Sun, Y.; Zhao, J.; Li, H.; Liu, M. Identification of laryngeal cancer prognostic biomarkers using an inflammatory gene-related, competitive endogenous RNA network. Oncotarget 2017, 8, 9525-9534. [CrossRef] [PubMed]

43. Bai, Z.; Shi, E.; Wang, Q.; Dong, Z.; Xu, P. A potential panel of two-long non-coding RNA signature to predict recurrence of patients with laryngeal cancer. Oncotarget 2017, 8, 69641-69650. [CrossRef] [PubMed]

44. Cerami, E.; Gao, J.; Dogrusoz, U.; Gross, B.E.; Sumer, S.O.; Aksoy, B.A.; Jacobsen, A.; Byrne, C.J.; Heuer, M.L.; Larsson, E.; et al. The cBio cancer genomics portal: An open platform for exploring multidimensional cancer genomics data. Cancer Discov. 2012, 2, 401-404. [CrossRef] [PubMed]

45. Gao, J.; Aksoy, B.A.; Dogrusoz, U.; Dresdner, G.; Gross, B.; Sumer, S.O.; Sun, Y.; Jacobsen, A.; Sinha, R.; Larsson, E.; et al. Integrative analysis of complex cancer genomics and clinical profiles using the cBioPortal. Sci. Signal 2013, 6, pl1. [CrossRef] [PubMed]

46. Nicolau-Neto, P.; Da Costa, N.M.; de Souza Santos, P.T.; Gonzaga, I.M.; Ferreira, M.A.; Guaraldi, S.; Moreira, M.A.; Seuánez, H.N.; Brewer, L.; Bergmann, A.; et al. Esophageal squamous cell carcinoma transcriptome reveals the effect of. Oncotarget 2018, 9, 16634-16647. [CrossRef]

47. Li, C.; Wong, W.H. Model-based analysis of oligonucleotide arrays: Expression index computation and outlier detection. Proc. Natl. Acad. Sci. USA 2001, 98, 31-36. [CrossRef]

48. Davis, S.; Meltzer, P.S. GEOquery: A bridge between the Gene Expression Omnibus (GEO) and BioConductor. Bioinformatics 2007, 23, 1846-1847. [CrossRef]

49. Wettenhall, J.M.; Smyth, G.K. limmaGUI: A graphical user interface for linear modeling of microarray data. Bioinformatics 2004, 20, 3705-3706. [CrossRef]

50. Carstensen, B.; Plummer, M.; Laara, E.; Hills, M. Epi: A Package for Statistical Analysis in Epidemiology. $\mathrm{R}$ package Version 2.40. Available online: https:/CRAN.R-project.org/package=Epi (accessed on 9 January 2020).

51. Therneau, T. A Package for Survival Analysis in S. Version 2.38. Available online: https://CRAN.R-project. org/package=survival (accessed on 9 January 2020).

52. Savage, R.; Cooke, E.; Darkins, R.; Xu, Y. BHC: Bayesian Hierarchical Clustering. R Package Version 1.38.0. Available online: https://www.bioconductor.org/packages/release/bioc/manuals/BHC/man/BHC.pdf (accessed on 9 January 2020).

53. De A Simão, T.; Souza-Santos, P.T.; de Oliveira, D.S.; Bernardo, V.; Lima, S.C.; Rapozo, D.C.; Kruel, C.D.; Faria, P.A.; Ribeiro Pinto, L.F.; Albano, R.M. Quantitative evaluation of SPRR3 expression in esophageal squamous cell carcinoma by qPCR and its potential use as a biomarker. Exp. Mol. Pathol. 2011, 91, 584-589. [CrossRef] 
54. Mermel, C.H.; Schumacher, S.E.; Hill, B.; Meyerson, M.L.; Beroukhim, R.; Getz, G. GISTIC2.0 facilitates sensitive and confident localization of the targets of focal somatic copy-number alteration in human cancers. Genome Biol. 2011, 12, R41. [CrossRef]

55. Bradburn, M.J.; Clark, T.G.; Love, S.B.; Altman, D.G. Survival analysis Part III: Multivariate data analysis-Choosing a model and assessing its adequacy and fit. Br. J. Cancer 2003, 89, 605-611. [CrossRef] [PubMed]

(C) 2020 by the authors. Licensee MDPI, Basel, Switzerland. This article is an open access article distributed under the terms and conditions of the Creative Commons Attribution (CC BY) license (http://creativecommons.org/licenses/by/4.0/). 